$\overline{\text { Original }}$

\title{
Bactericidal Action of Photo-Irradiated Aqueous Extracts from the Residue of Crushed Grapes from Winemaking
}

\author{
MANA TSUKADA ${ }^{1,4}$, HONG SHENG $^{2}$, MIKA TADA $^{3}$, TAKAYUKI MOKUDAI ${ }^{2}$, \\ SATOMI OIZUMI', TOSHIAKI KAMACHI ${ }^{2}$, AND YOSHIMI NIWANO ${ }^{2 *}$ \\ ${ }^{1}$ Graduate School of Bioscience and Biotechnology, Tokyo Institute of Technology, \\ 2-12-1-M6-7 Ookayama, Meguro-ku, Tokyo 152-8250, Japan \\ ${ }^{2}$ Tohoku University Graduate School of Dentistry, 4-1 Seiryo, Aoba-ku, Sendai 980-8575, Japan \\ ${ }^{3}$ Center for General Education, Tohoku Institute of Technology, 35-1, Yagiyama, Kasumicho, Taihaku-ku, \\ Sendai, 982-8577, Japan \\ ${ }^{4}$ HABA Laboratories Inc., 1-24-11, Kanda Sudacho, Chiyoda-ku, Tokyo 101-0041, Japan
}

Received 23 May, 2015/Accepted 6 October, 2015

\begin{abstract}
Our previous studies revealed that photo-irradiation of polyphenols could exert bactericidal action via reactive oxygen species (ROS). In the present study, the photo-irradiation-induced bactericidal activity of the aqueous extract from the residue of crushed grapes from winemaking was investigated in relation to ROS formation. Staphylococcus aureus suspended in the extract was irradiated with LED light at $400 \mathrm{~nm}$. This solution killed the bacteria, and a 3-4 log and a >5-log reduction of the viable counts were observed within 10 and $20 \mathrm{~min}$, respectively. LED light irradiation alone also killed the bacteria, but the viable counts were 2-4 log higher than those of the photo-irradiated extract. In contrast, almost no change occurred in the suspension without LED irradiation. When hydroxyl radical scavengers were added to the suspension, the bactericidal effect of the photo-irradiated extract was attenuated. Furthermore, electron spin resonance analysis demonstrated that hydroxyl radicals were generated by the photo-irradiation of the extract. The present study suggests that polyphenolic compounds in the extract exert bactericidal activity via hydroxyl radical formation upon photo-irradiation.
\end{abstract}

Key words : Extract from residue of winemaking / Bactericidal action / Hydroxyl radical / Hydrogen peroxide / Photo-oxidation of polyphenols.

\section{INTRODUCTION}

Polyphenolic compounds are noteworthy for their antioxidant activity (Kondo et al., 1999; Liu et al., 2000; Yilmaz and Toledo 2004). Besides their antioxidant activity, recent advances in polyphenol biochemistry have made it possible to apply their pro-oxidant potential to various fields such as anti-cancer treatment. For instance, it was reported that an important anticancer mechanism of plant polyphenols is mediated through intracellular copper mobilization and reactive oxygen species (ROS) generation, which is a characteristic feature of pro-oxidant properties of polyphenolic

*Corresponding author. Tel: +81-22-717-8298, Fax: +81-22717-8299, E-mail : niwano(a)m.tohoku.ac.jp compounds, leading to cancer cell death (Khan et al., 2014). We have also applied the pro-oxidant potential of polyphenols to the development of a novel disinfection technique (Nakamura et al., 2012; 2013; 2015). That is, exposing an aqueous solution of polyphenols to blue light led to photo-oxidation of the polyphenolic hydroxyl group, resulting in the generation of ROS in the presence of dissolved oxygen. Hydrogen peroxide $\left(\mathrm{H}_{2} \mathrm{O}_{2}\right)$ is produced via electron transfer from photooxidized polyphenols to the dissolved oxygen. The $\mathrm{H}_{2} \mathrm{O}_{2}$ is subsequently photolyzed by the blue light, resulting in the generation of hydroxyl radicals $(\cdot \mathrm{OH})$, which would be a main contributor of the bactericidal activity.

Food processing environments offer recyclable food resources. The residue of crushed and pressed grapes obtained in the winemaking process could be a candi- 
date for such resources because it would contain a lot of polyphenols. For instance, a high-resolution mass spectrometry coupled to suspect screening analysis with positive and negative ionization modes identified several hundred grape polyphenols, four flavonols, and some grape resveratrol trimers and tetramers which were found in grapes for the first time (Flamini et al., 2015). Thus, we focused on the residue of crushed and pressed grapes in the winemaking process as an untapped natural resource with antioxidant and pro-oxidant potential.

The purpose of the present study was to evaluate the bactericidal activity of the photo-irradiated aqueous extract of crushed and pressed grape residue obtained from the process of making white wine in relation to ROS formation as a potential pro-oxidant activity. Regarding the light source, a light emitting diode (LED) with a wavelength of $400 \mathrm{~nm}$ was used to avoid the possible adverse effect of ultraviolet (UV) light as in our previous studies (Nakamura et al. 2012; 2015), since UV is defined as an electromagnetic wave with a wavelength of $<400 \mathrm{~nm}$.

\section{MATERIALS AND METHODS}

\section{Reagents}

Reagents were purchased from the following sources: 5,5-dimethyl-1-pyrroline $\mathrm{N}$-oxide (DMPO) from Labotec (Tokyo, Japan); catalase from bovine liver, dimethyl sulfoxide (DMSO), and thiourea from Wako Pure Chemical Industries (Osaka, Japan); 4-hydroxy-2,2,6, 6-tetramethylpiperidine $\mathrm{N}$-oxyl (TEMPOL) from Sigma Aldrich (St. Louis, MO). All other reagents used were of analytical grade.

\section{Preparation of the aqueous extract}

Fruitage (including the peel and seeds) of the white wine grape variety Niagara harvested in Hokkaido, Japan was crushed and pressed to obtain a juice in the vinification process of white wine. The residue of crushed and pressed grapes was freeze-dried. Three times the volume of pure water (at the ratio of $3 \mathrm{~mL}$ pure water per $1 \mathrm{~g}$ powder) was added to the dried residue powder, and the resultant mixture was agitated at 150 rpm overnight at room temperature. The upper layer was taken and centrifuged at $3000 \mathrm{rpm}$ for $20 \mathrm{~min}$ to obtain a supernatant. Following membrane filtration ( $\phi$ $0.22 \mu \mathrm{m}$ ), the supernatant was subjected to total polyphenol determination by the Folin-Denis method in which gallic acid was used as a standard (Schanderl 1970). The aqueous extract solution (termed as the extract thereafter) was adjusted to contain $0.5 \mathrm{mg}$ total polyphenol $/ \mathrm{mL}$ with pure water and stored at $-80^{\circ} \mathrm{C}$ until assayed.

\section{Light source}

An experimental device equipped with an LED with a wavelength of $400 \mathrm{~nm}$ (NHH105UV, Lustrous Technology, Shiji, Taiwan) was used according to our previous study (Nakamura et al., 2012; 2013; 2015). The output power of the LED, measured using a power meter (FieldMate, Coherent, Santa Clara, CA), was set to be $400 \mathrm{~mW}$ per LED corresponding to an irradiance of 130 $\mathrm{mW} / \mathrm{cm}^{2}$ at a distance of $15 \mathrm{~mm}$ from the LED. A fourclear-sided methacrylate plastic cuvette (Fisherbrand Disposable Cuvette, size: $12 \times 12 \times 45(\mathrm{H}) \mathrm{mm}$, light transmission rate at $400 \mathrm{~nm}$ : 90\%, Thermo Fisher Scientific K. K., Yokohama, Japan) containing the sample was placed in the experimental device. LED-light irradiation was performed toward both sides of the plastic cuvette (total irradiance: $260 \mathrm{~mW} / \mathrm{cm}^{2}$ ).

For analyses of wavelength dependence of $\mathrm{H}_{2} \mathrm{O}_{2}$ generation and of bactericidal activity, an LED spot curing device (OmniCure LX400+, Lumen Dynamics Group, Ontario, Canada) with the specific heads emitting the light at wavelengths of 365, 385 and $400 \mathrm{~nm}$, and a dental LED light curing unit (G-Light Prima-II, GC, Tokyo, Japan) with a wavelength of $465 \mathrm{~nm}$ were used.

\section{Bactericidal assay}

Staphylococcus aureus JCM 2413 purchased from the Japan Collection of Microorganisms, RIKEN BioResource Center (Wako, Japan) was used. A bacterial suspension was prepared in sterile physiological saline from a culture grown on brain heart infusion $(\mathrm{BHI})$ agar (Becton Dickinson Labware, Franklin Lakes, $\mathrm{NJ}$ ) aerobically at $37^{\circ} \mathrm{C}$ for $12 \mathrm{~h}$. In a plastic cuvette, $450 \mu \mathrm{L}$ of the extract or pure water was mixed with $50 \mu \mathrm{L}$ of the bacterial suspension to reach final concentration of approximately $10^{7}$ colony forming units (CFU)/mL for the bacteria. Then, the samples were exposed to the LED light for 10 or 20 min. After irradiation, $50 \mu \mathrm{L}$ of the sample was mixed with an equal volume of sterile catalase solution (5000 $\mathrm{U} / \mathrm{mL}$ in phosphate buffered saline, $\mathrm{pH} 7.4$ ) to terminate the bactericidal effect of $\mathrm{H}_{2} \mathrm{O}_{2}$ that might be generated by photo-oxidation of polyphenols in the extract. A 10-fold serial dilution of the mixture was prepared using sterile physiological saline, and $10 \mu \mathrm{L}$ of the diluted solution was seeded onto a $\mathrm{BHI}$ agar plate. The agar plates were cultured in the same way as described above for 2 days, and the $\mathrm{CFU} / \mathrm{mL}$ was determined. In addition, a bacterial suspension that was kept for 10 and 20 min in a light shielding box instead of being exposed to the LED light was subjected to the same procedure. The bacterial initial count (inoculum size) was also evaluated by the viable counting method.

To examine if the bactericidal effect of the photo-irradiated extract could be attributable to $\cdot \mathrm{OH}$, DMSO and thiourea, which are well-known $\cdot \mathrm{OH}$ scavengers (Dorfman 
and Adams, 1973; Halliwell and Gutteridge, 2007), were added to the reaction mixture. The reaction mixture consisting of $425 \mu \mathrm{L}$ of the extract, $50 \mu \mathrm{L}$ of the bacterial suspension and $25 \mu \mathrm{L}$ of DMSO or thiourea was prepared to reach final concentrations of approximately $10^{7} \mathrm{CFU} /$ $\mathrm{mL}$ for the bacteria and $700 \mathrm{mM}$ for DMSO or $150 \mathrm{mM}$ for thiourea. Then, the sample was irradiated with the LED light for 10 or 20 min. The CFU was determined after each treatment as described above. All tests were performed in triplicate.

\section{Electron spin resonance (ESR) analysis of $\cdot \mathrm{OH}$ and colorimetric determination of $\mathrm{H}_{2} \mathrm{O}_{2}$}

Qualitative and quantitative analyses of $\cdot \mathrm{OH}$ generated by photo-irradiation of the extract were performed using an ESR spin trapping technique as described in our earlier study (Nakamura et al., 2010). An aliquot $(483 \mu \mathrm{L})$ of the extract was mixed with $17 \mu \mathrm{L}$ of DMPO in a plastic cuvette to reach a final concentration of 300 $\mathrm{mM}$ for DMPO. Then, the sample was irradiated with the LED light for 0, 10, 20, and $60 \mathrm{~s}$. After irradiation, the sample was transferred to a quartz cell for ESR spectrometry, and the ESR spectrum was recorded on an X-band ESR spectrometer (JES-FA-100; JEOL, Tokyo, Japan). The measurement conditions for ESR were as follows: field sweep, 331.89-341.89 mT; field modulation frequency, $100 \mathrm{kHz}$; field modulation width, $0.1 \mathrm{mT}$; amplitude, 200; sweep time, 2 min; time constant, $0.03 \mathrm{~s}$; microwave frequency, $9.420 \mathrm{GHz}$; and microwave power, $4 \mathrm{~mW}$. TEMPOL $(2 \mu \mathrm{M})$ was used as a standard to calculate the concentration of the spintrapped radicals, and the ESR spectrum of manganese $\left(\mathrm{Mn}^{2+}\right)$ held in the ESR cavity was used as an internal standard.

To examine if $\cdot \mathrm{OH}$ is continuously generated during LED-light irradiation for 20 min, after 20 min of irradiation DMPO was added to the photo-irradiated extract to a final concentration of $300 \mathrm{mM}$. Immediately after addition of DMPO, the sample was further irradiated with the LED-light for $10 \mathrm{~s}$. Then ESR analysis was performed as described above.

DMPO-OH, a spin adduct of $\cdot \mathrm{OH}$, can be formed even in the absence of $\cdot \mathrm{OH}$ under certain conditions (Britigan et al., 1986). Consequently, additional ESR analysis was conducted to confirm if the DMPO-OH was derived from the reaction between $\cdot \mathrm{OH}$ and DMPO. If $\cdot \mathrm{OH}$ is generated, the intensity of DMPO-OH signal would decrease and a signal for a spin adduct of the methyl radical $\left(\mathrm{DMPO}-\mathrm{CH}_{3}\right)$ would appear when an $\cdot \mathrm{OH}$ scavenger containing a methyl group is added to the reaction system (Sato et al., 2011). The reaction mixture consisting of $433 \mu \mathrm{L}$ of the extract, $17 \mu \mathrm{L}$ of DMPO, and $50 \mu \mathrm{L}$ of pure water or $14 \mathrm{M} \mathrm{DMSO}$ was prepared to reach final concentrations of $300 \mathrm{mM}$ for DMPO and 1.4
M for DMSO. Then, the sample was irradiated with the LED light for $20 \mathrm{~s}$. ESR analysis was performed as described above.

For $\mathrm{H}_{2} \mathrm{O}_{2}$ determination, the samples were treated similarly to the case with the ESR analysis. That is, $483 \mu \mathrm{L}$ of the extract was mixed with $17 \mu \mathrm{L}$ of pure water instead of DMPO in a plastic cuvette followed by LED-light irradiation for 10 min. Immediately after the irradiation, the $\mathrm{H}_{2} \mathrm{O}_{2}$ concentration was determined by a colorimetric method based on the peroxide-mediated oxidation of $\mathrm{Fe}^{2+}$ followed by the reaction of $\mathrm{Fe}^{3+}$ with xylenol orange (Jiang et al., 1990). To confirm if the generated $\mathrm{H}_{2} \mathrm{O}_{2}$ responds to the catalytic action of catalase, $250 \mu \mathrm{L}$ of the extract was mixed with $250 \mu \mathrm{L}$ of $0.1 \mathrm{M} \mathrm{Na-K}$ phosphate buffer (PB, pH7.4) or catalase solution (5000 U/ $\mathrm{mL}$ in $0.1 \mathrm{M} \mathrm{PB}$ ) followed by LED-light irradiation for 10 min. As a negative control, $500 \mu \mathrm{L}$ of the mixture of the extract and 0.1 M PB was kept in a light-shielding box for 10 min. Then the $\mathrm{H}_{2} \mathrm{O}_{2}$ concentration was similarly determined. All tests were performed in triplicate.

\section{Analyses of the wavelength dependence of $\mathrm{H}_{2} \mathrm{O}_{2}$ generation and of the bactericidal activity}

According to the ultraviolet (UV)-visible absorption spectrum of different dilutions of the extract (Fig.1), the value of absorbance decreased with the increase of wavelength in the range between $300-600 \mathrm{~nm}$. Thus, it was hypothesized that UV-light irradiation $(<400 \mathrm{~nm})$ generated $\mathrm{H}_{2} \mathrm{O}_{2}$ more efficiently than visible light irradiation if the reaction is caused by the absorbed light energy. To examine the wavelength dependence of $\mathrm{H}_{2} \mathrm{O}_{2}$ generation, the extract put in a black microplate well (96-well) was irradiated with each LED light in a vertical direction. An output power was measured using the laser power meter (FieldMate, Coherent) and set at $230 \mathrm{~mW}$. The diameter of the irradiation field was set to equal that of the well $(6.4 \mathrm{~mm})$ so that almost all of the light could pass through the test solution. Thus, the irradiance corresponding to the output power of 230 $\mathrm{mW}$ was calculated to be $715 \mathrm{~mW} / \mathrm{cm}^{2}$. In a microplate

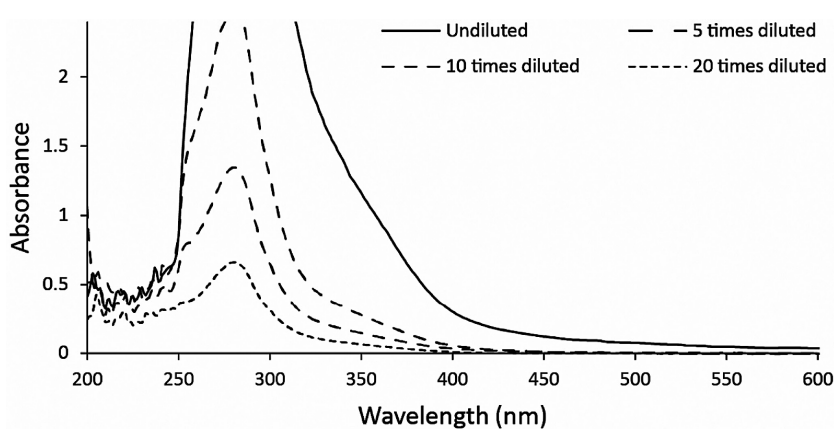

FIG. 1. Ultraviolet-visible spectra of the aqueous extract from the residue of crushed grapes. 
well, $200 \mu \mathrm{L}$ of the extract was irradiated with LED light for 3 min. After irradiation, the $\mathrm{H}_{2} \mathrm{O}_{2}$ determination was performed as described above. All tests were performed in triplicate.

To examine the wavelength dependence of the bactericidal activity, in each well of the black microplate well (96-well), $180 \mu \mathrm{L}$ of the extract or pure water was mixed with $20 \mu \mathrm{L}$ of the bacterial suspension to reach final concentration of approximately $10^{6}$ colony forming units (CFU) $/ \mathrm{mL}$ for the bacteria. Then, the samples were exposed to LED-light for $5 \mathrm{~min}$ as described in the analysis of $\mathrm{H}_{2} \mathrm{O}_{2}$ generation. After irradiation, the $\mathrm{CFU}$ was determined after each treatment as described above.

\section{Liquid chromatography/mass spectrometry (LC/ MS) analyses of the extract}

For LC/MS analyses, the extract was diluted to a concentration of $0.04 \mathrm{mg}$ total polyphenol equivalent/ $\mathrm{mL}$ with pure water followed by passage through a filter (pore size, $0.2 \mu \mathrm{m}$ ). The resultant sample was injected into the electrospray ion source (Ultraspray $2^{\mathrm{TM}}$ Dual ESI source), PerkinElmer, Inc., Waltham, MA, USA) of a time-of-flight mass spectrometer (AxION 2 TOF MS, PerkinElmer Inc.) coupled to the PerkinElmer Flexar ${ }^{\mathrm{TM}}$ FX-15LC (PerkinElmer, Inc.). Chromatographic separation was undertaken on the $\mathrm{C} 18$ column $(2.1 \times 150 \mathrm{~mm}$ Brownlee SPP 2.7, PerkinElmer) at $40^{\circ} \mathrm{C}$. With regard to gradient elution, solvent $\mathrm{A}$ was $0.1 \%$ formic acid, and $B$ was acetonitrile containing $0.1 \%$ formic acid. Gradient elution was $0-10$ min and $0-100 \% \mathrm{~B}$. The flow rate was $0.4 \mathrm{~mL} / \mathrm{min}$, and the injection volume was $10 \mu \mathrm{L}$. Electrospray ionization (ESI)-mass spectrum was recorded for $10 \mathrm{~min}$ in the $\mathrm{m} / \mathrm{z}$ region from 100 to $1000 \mathrm{Da}$ with the following instrument parameters: drying gas heater; $400^{\circ} \mathrm{C}$, nebulizing gas; $80 \mathrm{PSI}$, capillary exit voltage; 120 $\mathrm{V}$. LC/MS analyses were undertaken by high-resolution electrospray ionization-mass spectrometry $(R \geq 12,000$; tolerance for mass accuracy $=5 \mathrm{ppm}$ ). As standards, (+)-catechin (Tokyo Chemical Industry, Tokyo, Japan) was used.

\section{Statistical analyses}

Statistical significance in the CFU/mL obtained in the bactericidal assay was assessed by the Tukey-Kramer HSD multi-comparison test. The analysis for the bactericidal assay was performed following logarithmic conversion. When colonies were not detected, the value of the detection limit $\left(10^{2} \mathrm{CFU} / \mathrm{mL}\right)$ was used for the statistical analysis. Regarding the yield of $\mathrm{H}_{2} \mathrm{O}_{2}$ in pure water and the extract with or without LED-light irradiation, since $\mathrm{H}_{2} \mathrm{O}_{2}$ was not detected in the two pure water groups, statistical significance for the remaining two groups was assessed by the Student's t-test. Statistical significances in the other experiments were assessed by the Tukey-
Kramer HSD multi-comparison test. $\mathrm{P}<0.05$ was considered significant.

\section{RESULTS}

\section{Bactericidal assay}

The results of the bactericidal assay are summarized in Fig.2. Under the conditions without the LED-light irradiation, the extract kept in a light-shielding box for 10 and 20 min showed almost no bactericidal activity in comparison with that of the corresponding pure water groups. LED-light irradiation alone showed somewhat bactericidal activity. That is, the LED-light irradiation of pure water for 10 and 20 min showed approximately a $1.5 \mathrm{log}$ and $3 \mathrm{log}$ reduction of viable bacterial counts $(\mathrm{CFU} / \mathrm{mL})$, respectively, when compared with the corre-

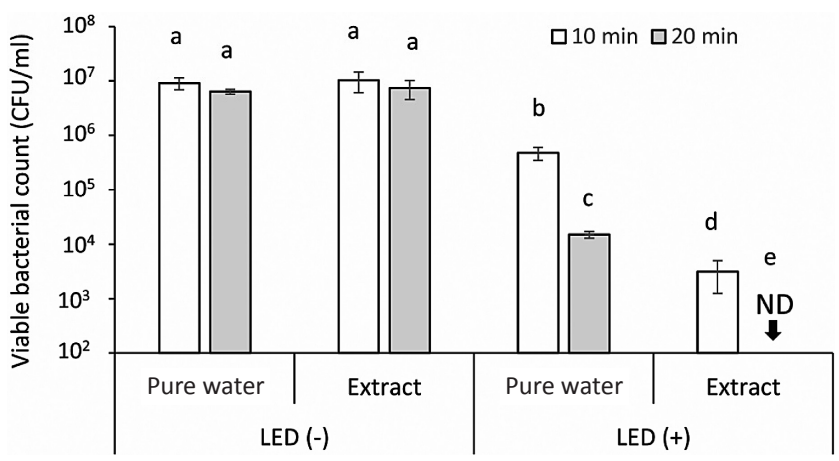

FIG. 2. The number of viable Staphylococcus aureus in the suspension after each treatment. Each value is the mean of triplicate determinations with the standard deviation. Significant differences $(p<0.01)$ within each group are denoted by different letters (i.e., bars with the same letter are not significantly different). ND: Not detected.

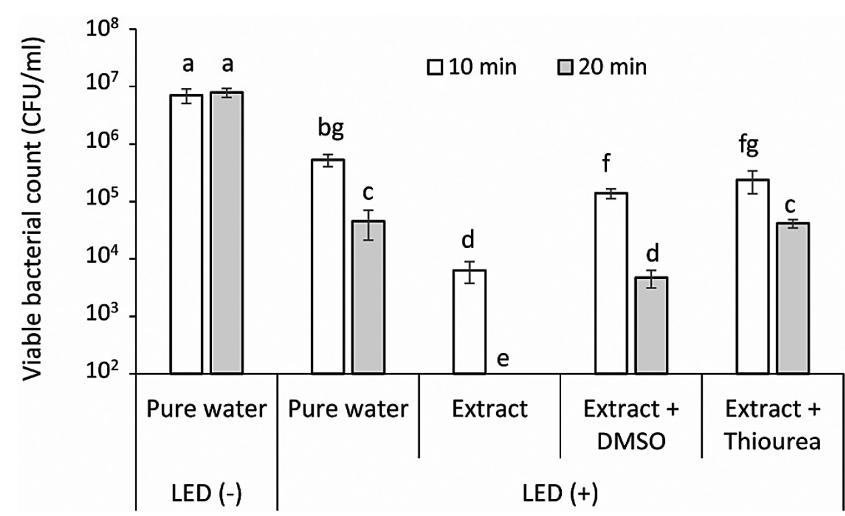

FIG. 3. Influence of $\cdot \mathrm{OH}$ scavengers on the bactericidal effect of photo-irradiated extract. Each value is the mean of triplicate determinations with the standard deviation. Significant differences $(p<0.01)$ within each group are denoted by different letters (i.e., bars with the same letter are not significantly different). 


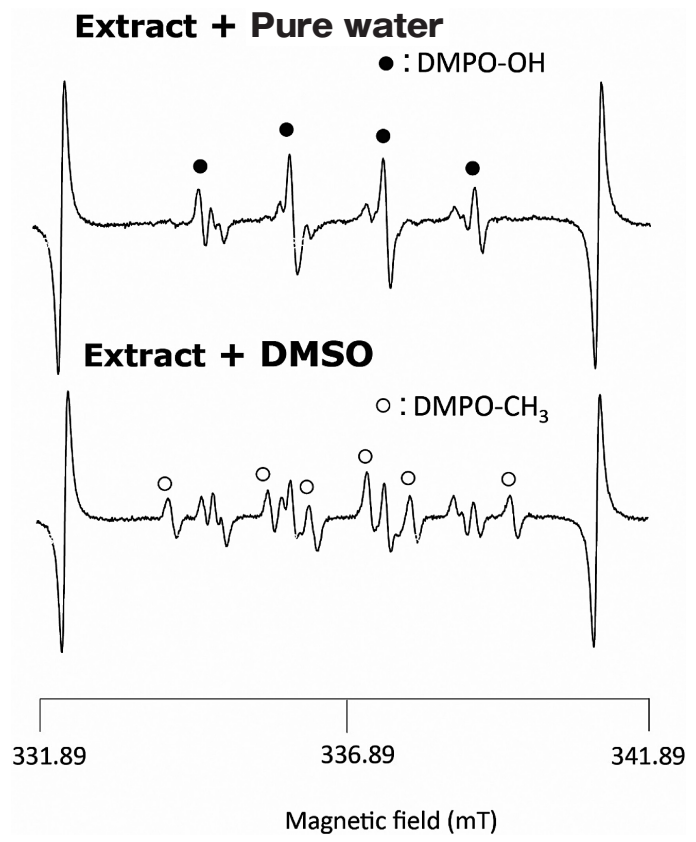

FIG. 4. Representative ESR spectra obtained by the LEDlight irradiation of the extract in the absence or presence of 1.4 M DMSO. The LED-light irradiation was performed for 10 min.

sponding pure water groups without the LED-light irradiation. Furthermore, the LED-light irradiation of the extract for 10 min killed the bacteria effectively with an approximately 4 log reduction, and the LED-light irradiation for 20 min achieved a $>5$ log reduction.

In the experiment for examining the effect of $\cdot \mathrm{OH}$ scavengers, DMSO and thiurea significantly attenuated the bactericidal effect of the photo-irradiated extract (Fig.3).

\section{ESR analysis of $\cdot \mathrm{OH}$ and colorimetric determina- tion of $\mathrm{H}_{2} \mathrm{O}_{2}$}

When the extract with $300 \mathrm{mM}$ DMPO was irradiated with the LED-light, the ESR signal of the $\cdot \mathrm{OH}$ spin adduct (DMPO-OH) was detected (Fig.4). The presence of the spin adduct was confirmed by hyper fine coupling constants of $\mathrm{aN}=\mathrm{aH}=1.49 \mathrm{mT}$ for DMPO-OH (Buettner 1987). Addition of DMSO to the reaction mixture decreased the signal of DMPO-OH, and a signal for DMPO- $\mathrm{CH}_{3}$ was observed, which was identified by its hyper fine coupling constants of $\mathrm{aN}=1.64 \mathrm{mT}$ and $\mathrm{aH}=$ 2.35 mT (Britigan et al., 1986; Buettner, 1987). This suggests that the DMPO-OH was generated by the reaction between free $\cdot \mathrm{OH}$ and DMPO.

As shown in Fig.5, the yields of DMPO-OH after LED-light irradiation of the extract increased linearly with time up to $20 \mathrm{~s}$, but the yield seemed to have reached a saturation level after that since LED-light irradiation for

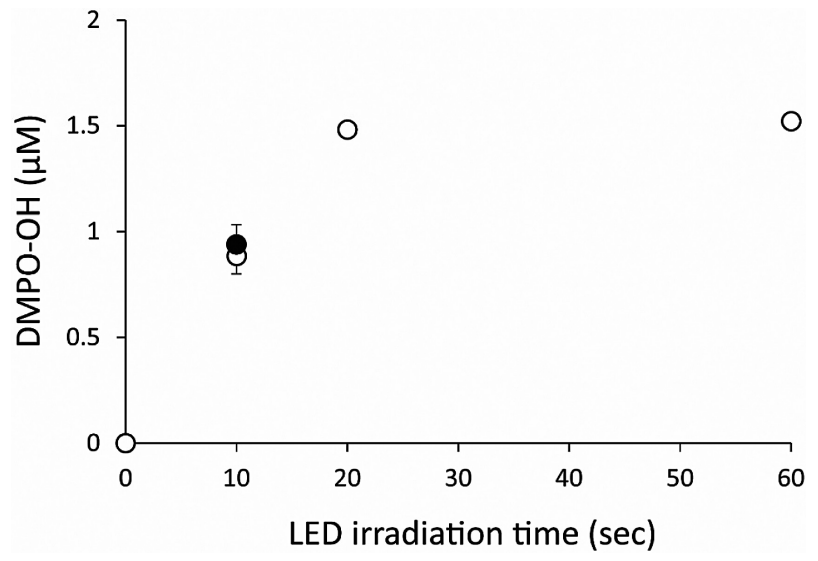

FIG. 5. Yield of $\cdot \mathrm{OH}(\bigcirc)$ generated by the LED-light irradiation of the extract for $0,10,20$, and $60 \mathrm{~s}$, and of $\cdot \mathrm{OH}(\mathbf{O})$ generated by the $10 \mathrm{~s}$ irradiation of the extract that was subjected to prior photo-irradiation for 20 min without DMPO. Each value is the mean of triplicate determinations with the standard deviation.

$60 \mathrm{~s}$ resulted in a similar DMPO-OH yield to that in LED-light irradiation for $20 \mathrm{~s}$ possibly due to the decay of DMPO-OH (Nakamura et al., 2010). To examine if -OH was continuously being generated during LED-light irradiation, the photo-irradiated extract for 20 min was furthered irradiated with LED light for $10 \mathrm{~s}$ in the presence of $300 \mathrm{mM}$ DMPO, and results showed a similar yield of DMPO-OH (around $0.9 \mu \mathrm{M}$ ) to that after $10 \mathrm{~s}$ irradiation of the extract without prior irradiation. ESR signals other than that of DMPO-OH, such as DMPO$\mathrm{OOH}$, were not clearly observed under the conditions used in the present study.

When the extract was irradiated with the LED light, $\mathrm{H}_{2} \mathrm{O}_{2}$ was prominently generated (Fig.6A). In contrast, only a small amount of $\mathrm{H}_{2} \mathrm{O}_{2}$ was found in the extract without the irradiation, and $\mathrm{H}_{2} \mathrm{O}_{2}$ was not detected in the pure water irrespective of whether it was irradiated or not. The average yield of $\mathrm{H}_{2} \mathrm{O}_{2}$ generated in the extract with the LED-light irradiation for 10 min was approximately $300 \mu \mathrm{M}$. As shown in Fig.6B, the $\mathrm{H}_{2} \mathrm{O}_{2}$ generated by LED irradiation was almost completely scavenged by catalase.

\section{Analysis of the wavelength dependence of $\mathrm{H}_{2} \mathrm{O}_{2}$ generation and of the bactericidal activity}

There were significant differences in the absorbance of the extract at $365,385,400$, and $465 \mathrm{~nm}$, and the absorbance increased as the wavelength was shorter (Fig.7A). In addition, the yield of $\mathrm{H}_{2} \mathrm{O}_{2}$ in the photo-irradiated extract was significantly affected by the wavelength of light (Fig.7B). When the extract was irradiated with the light at the four wavelengths, the shorter the wavelength was, the more $\mathrm{H}_{2} \mathrm{O}_{2}$ was generated. 
A

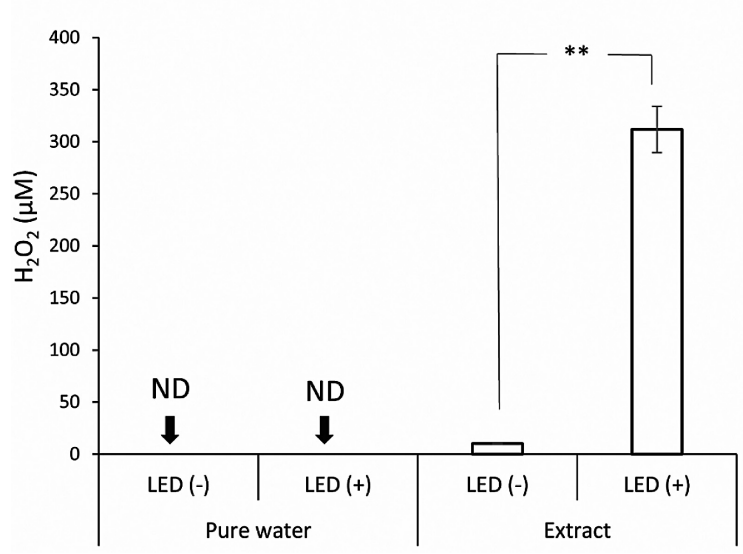

B

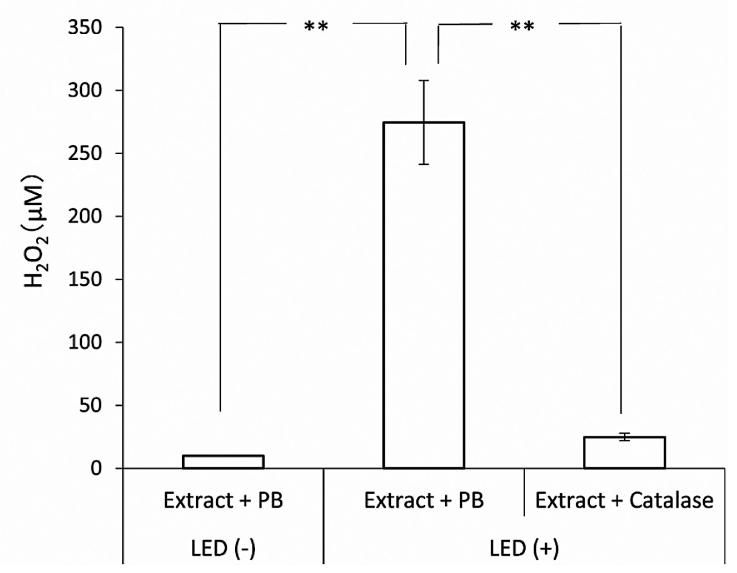

FIG. 6. Yield of $\mathrm{H}_{2} \mathrm{O}_{2}$ generated by the LED-light irradiation of samples for $10 \mathrm{~min}(\mathrm{~A})$, and of $\mathrm{H}_{2} \mathrm{O}_{2}$ generated in the absence or presence of catalase (B). PB stands for $0.1 \mathrm{M} \mathrm{Na}-\mathrm{K}$ phosphate buffer (pH7.6) that was used for dissolving catalase. Each value is the mean of triplicate determinations with the standard deviation. Significant differences between the two groups are shown as ${ }^{*} p<0.01$. ND: Not detected.

\section{A}

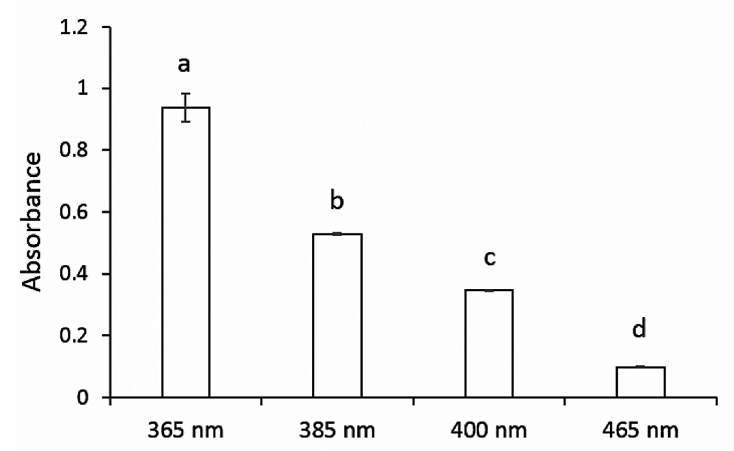

B

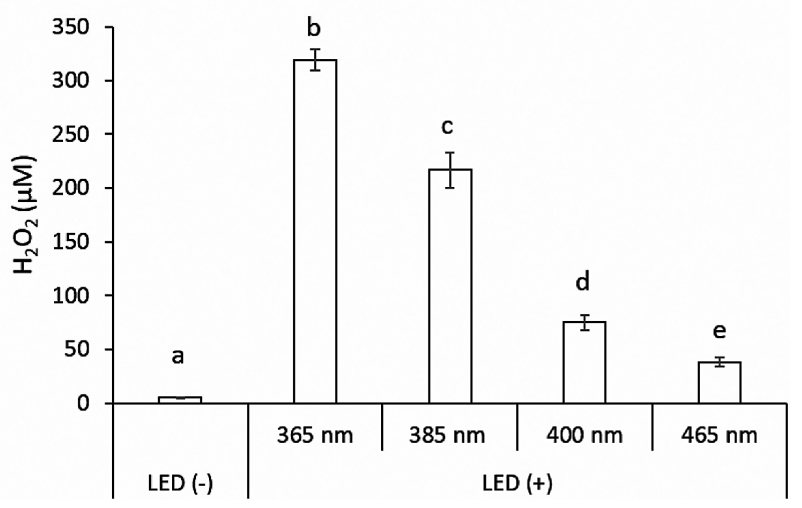

FIG. 7. Absorbance of the aqueous extract from the residue of crushed grapes at each wavelength $(A)$ and quantification of $\mathrm{H}_{2} \mathrm{O}_{2}$ generated in the photo-irradiated extract at each wavelength (B). Each value is the mean of triplicate determinations with the standard deviation. Significant differences $(p<0.01)$ within each group are denoted by different letters (i.e., bars with the same letter are not significantly different).

Similar to $\mathrm{H}_{2} \mathrm{O}_{2}$ generation, potent bactericidal activity was obtained at the wavelengths of 365 and $385 \mathrm{~nm}$ whilst almost no bactericidal activity was found at the wavelengths of 400 and $465 \mathrm{~nm}$ under the experimental conditions with an inoculum size of $1 \times 10^{6} \mathrm{CFU} / \mathrm{mL}$ and irradiation time of 3 min (Fig.8). As for the wavelength of 365 and $385 \mathrm{~nm}$, LED-light irradiation alone had some bactericidal activity with a 2-log and a 1 log reduction of viable bacterial count, respectively.

\section{Liquid chromatography/mass spectrometry (LC/ MS) analyses of the extract}

A representative mass spectrum of the three peaks with $\mathrm{m} / \mathrm{z}$ of $291.0867,292.0902$, and 293.0930 which correspond to the main ingredient and its two isotopic ingredients, respectively, is shown in Fig.9. The ESI mass spectrum clearly showed that $(+)$-catechin (calcd. for $\left.\mathrm{C}_{15} \mathrm{H}_{15} \mathrm{O}_{6}, 291.0863\right)$ was contained in the extract.

\section{DISCUSSION}

The present study demonstrated that after the LEDlight irradiation at $400 \mathrm{~nm}$, the aqueous extract of the crushed grape residue obtained from the process of making white wine exerted a bactericidal effect and reduced the CFU by $>5$ log within 20 min. Because $\cdot \mathrm{OH}$ was detected by the ESR analysis and the bactericidal effect was attenuated by $\cdot \mathrm{OH}$ scavengers, it was 


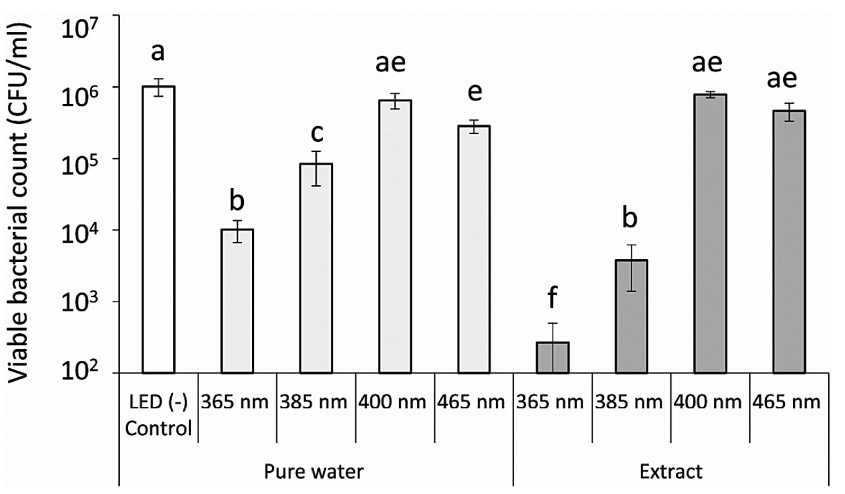

FIG. 8. Influence of wavelength on the bactericidal effect of the photo-irradiated extract. Each value is the mean of triplicate determinations with the standard deviation. Significant differences $(p<0.05)$ within each group are denoted by different letters (i.e., bars with the same letter are not significantly different).

suggested that the major contributor to the bactericidal effect of the photo-irradiated extract was $\cdot \mathrm{OH}$. Regarding the mild bactericidal potential of the LED-light irradiation alone, although the underlying mechanism is not clear at the present time, this finding agrees with an earlier study showing that irradiation with ultraviolet or visible blue light could exert bactericidal action depending on the level of irradiation (Vermeulen et al., 2008).

According to the ESR analysis, the average amount of $\cdot \mathrm{OH}$ generated by LED-light irradiation of the extract for $10 \mathrm{~s}$ was $0.88 \mu \mathrm{M}$. Prior photo-irradiation of the extract for 20 min did not affect the DMPO-OH yield produced by the subsequent irradiation for $10 \mathrm{~s}$, suggesting that - $\mathrm{OH}$ was continuously generated at least during the LED irradiation for 20 min. Thus, total amount of $\cdot \mathrm{OH}$ produced by LED-light irradiation for 20 min would be around $100 \mu \mathrm{M}$. Our earlier result using photolysis of hydrogen peroxide as a $\cdot \mathrm{OH}$ generation system suggested that $200-300 \mu \mathrm{M} \cdot \mathrm{OH}$ yielded in 3 min would be needed to produce a $>5$ log reduction in $S$. aureus (Ikai et al., 2010). Thus, the amount of $\cdot \mathrm{OH}$ obtained in the present study would be enough to kill bacteria in 10 to 20 min. In contrast, the amount of $\mathrm{H}_{2} \mathrm{O}_{2}$ determined after 10 min irradiation was around $300 \mu \mathrm{M}$, and the level seemed to be relatively low compared to the estimated amount of $\cdot \mathrm{OH}$ (around $50 \mu \mathrm{M}$ for $10 \mathrm{~min}$ ). However, $\mathrm{H}_{2} \mathrm{O}_{2}$ generated by LED-light irradiation possibly due to photo-oxidation of hydroxyl groups of polyphenolic compounds in the extract would be continuously photolyzed to generate $\cdot \mathrm{OH}$. Thus, the net amount of $\mathrm{H}_{2} \mathrm{O}_{2}$ would be much higher than $300 \mu \mathrm{M}$.

Although the extract does not have an absorption peak around $365-465 \mathrm{~nm}$, it absorbs the light somehow in the range of those wavelengths. Indeed, there were significant differences in the absorbance at 365,385 ,

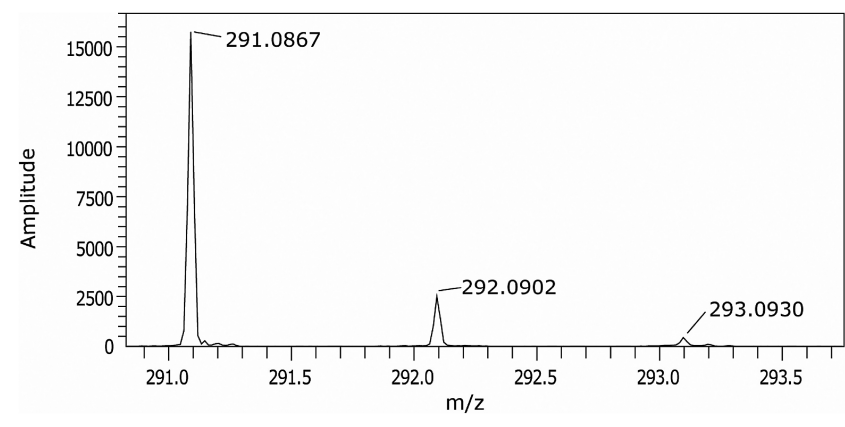

FIG. 9. A representative mass spectrum of the three peaks obtained from the extract with $\mathrm{m} / \mathrm{z}$ of $291.0867,292.0902$, and 293.0930 which correspond to the main ingredient of $(+)$ catechin and its two isotopic ingredients

400 , and $465 \mathrm{~nm}$, and absorption of the light by the extract increased as the wavelength was shorter. Based on this finding, further analyses were conducted to examine if the yield of $\mathrm{H}_{2} \mathrm{O}_{2}$ and bactericidal activity depended on the wavelength of light. The results showed that $\mathrm{H}_{2} \mathrm{O}_{2}$ generation and bactericidal activity under the LED-light irradiation increased inversely with the wavelength. In other words, the yield of $\mathrm{H}_{2} \mathrm{O}_{2}$ correlated well with bactericidal activity.

In addition to the absorption of the light, the photon energy of light would also be responsible for the increased $\mathrm{H}_{2} \mathrm{O}_{2}$ formation since the photon energy is inversely proportion to the wavelength as shown by the following equation. That is, $E=h c / \lambda$ where $E$ is energy of a photon, $\mathrm{h}$ is Planck's constant, $\mathrm{c}$ is the speed of light, and $\lambda$ is the wavelength of the light. These findings suggest that the reaction of $\mathrm{H}_{2} \mathrm{O}_{2}$ generation via photoirradiation of the extract is originally derived from photooxidation in which the light energy absorbed by the extract triggers the oxidation of hydroxyl groups of polyphenolic compounds in the extract. Regarding the application of the photo-irradiated extract, a light source emitting wavelengths less than $400 \mathrm{~nm}$ could make it possible not only to enhance the bactericidal action but to shorten the treatment time. This means that the technique could be applied to disinfection processes in various fields once the safety of the technique is verified.

A possible scheme for the bactericidal action via $\cdot \mathrm{OH}$ formation is illustrated in Fig.10. Firstly, the hydroxyl group of the polyphenolic compounds contained in the extract would be oxidized by the photo-irradiation ( $\lambda$ $=400 \mathrm{~nm}$ ). Secondly, because of the oxidation, a protoncoupled electron transfer to dissolved oxygen would result in $\mathrm{H}_{2} \mathrm{O}_{2}$ generation as shown in Fig.6 (Arakawa et al., 2004), followed by photolysis of $\mathrm{H}_{2} \mathrm{O}_{2}$ (Ikai et al., 2010). Finally, the $\cdot \mathrm{OH}$ generated by photolysis would cause oxidative damage to the bacterial cells. In the series of reactions, the photo-irradiation would probably 


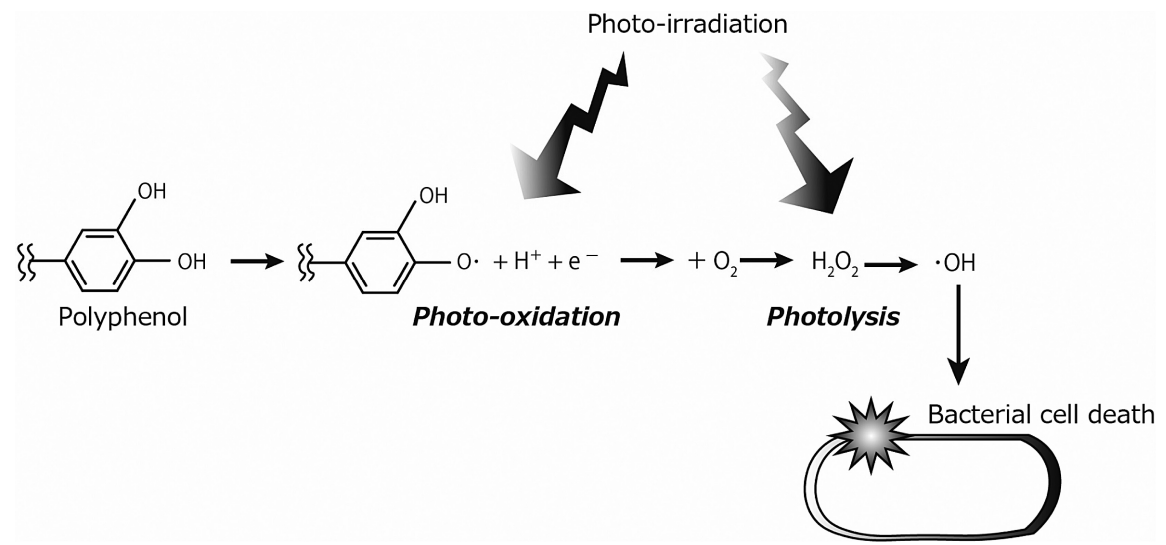

FIG. 10. Proposed mechanism of the bactericidal action in photo-irradiation of the extract.

function in two different ways, that is, photo-oxidation of polyphenolic compounds and photolysis of $\mathrm{H}_{2} \mathrm{O}_{2}$ as reported in our previous study (Nakamura et al., 2012). Regarding the polyphenolic compounds in the extract, (+)-catechin was detected by the LC/MS analysis. Since it is speculated that relatively water soluble polyphenolic compounds would be contained in the extract, further study is required to search for such compounds.

The present study suggests that photo-irradiated aqueous extract from the residue of crushed grapes from winemaking could be a recyclable food resource for a novel disinfection technique. Aqueous extracts are regarded as relatively safe because they are obtained from residues of crushed grapes. The other advantageous point is that the $\cdot \mathrm{OH}$ is only generated in these extracts during photo-irradiation because of the extremely short life of $\cdot \mathrm{OH}$ as $<10^{9} \mathrm{~s}$ (Roots and Okada, 1975; Pryor, 1986), suggesting that its generation is controllable through termination of the light irradiation. In other words, the residual toxicity would probably be negligible.

\section{ACKNOWLEDGEMENTS}

This research was supported by the Ministry of Education, Culture, Sports, Science and Technology Japan, Grant-in-Aid for Scientific Research (C), 26460116, 2014, and the Ministry of Education, Science, Sports and Culture, Japan, Strategic Research Foundation Grant-in-Aid for Private Universities, S1312001, 2013.

\section{REFERENCES}

Arakawa, H., Maeda, M., Okubo, S. and Shimamura, T. (2004) Role of hydrogen peroxide in bactericidal action of catechin. Biol. Pharm. Bull., 27, 277-281.

Britigan, B. E., Rosen, G. M., Chai, Y., and Cohen, M. S. (1986) Do human neutrophils make hydroxyl radical? Determination of free radicals generated by human neutrophils activated with a soluble or particulate stimulus using electron paramagnetic resonance spectrometry. J. Biol. Chem., 261, 44264431.

Buettner, G. R. (1987) Spin trapping: ESR parameters of spin adducts. Free Radic. Biol. Med., 3, 259-303.

Dorfman, L. M., and Adams, G. E. (1973) Reactivity of the hydroxyl radical in aqueous solutions, pp.1-59, Springfield, VA: Natl. Bur. Stand., (NSRDS-NBS no. 46).

Flamini, R., De Rosso, M., and Bavaresco, L. (2015) Study of Grape Polyphenols by Liquid Chromatography-HighResolution Mass Spectrometry (UHPLC/QTOF) and Suspect Screening Analysis. J. Anal. Methods Chem., 2015, 350259.

Halliwell, B., and Gutteridge, J. M. (2007) Hydroxyl radical. In Free radicals in biology and medicine, Forth edition, pp.4245, Oxford University Press: Oxford.

Ikai, H., Nakamura, K., Shirato, M., Kanno, T., Iwasawa, A., Sasaki, K., Niwano, Y., and Kohno, M. (2010) Photolysis of hydrogen peroxide, an effective disinfection system via hydroxyl radical formation. Antimicrob. Agents Chemother., 54, 5086-5091.

Jiang, Z. Y., Woollard, A. C., and Wolff, S. P. (1990) Hydrogen peroxide production during experimental protein glycation. FEBS Lett., 268, 69-71.

Khan, H. Y., Zubair, H., Faisal, M., Ullah, M. F., Farhan, M., Sarkar, F. H., Ahmad, A., and Hadi, S. M. (2014) Plant polyphenol induced cell death in human cancer cells involves mobilization of intracellular copper ions and reactive oxygen species generation: a mechanism for cancer chemopreventive action. Mol. Nutr. Food Res., 58, 437-446.

Kondo, K., Kurihara, M., Miyata, N., Suzuki, T., and Toyoda, M. (1999) Scavenging mechanisms of (-)-epigallocatechin gallate and (-)-epicatechin gallate on peroxyl radicals and formation of superoxide during the inhibitory action. Free Radic. Biol. Med., 27, 855-863.

Liu, Z., Ma, L. P., Zhou, B., Yang, L., and Liu, Z. L. (2000) Antioxidative effects of green tea polyphenols on free radical initiated and photosensitized peroxidation of human low density lipoprotein. Chem. Phys. Lipids, 106, 53-63.

Nakamura, K., Ishiyama, K., Sheng, H., Ikai, H., Kanno, T., and Niwano, Y. (2015) Bactericidal Activity and Mechanism of Photoirradiated Polyphenols against Gram-Positive and -Negative Bacteria. J. Agric. Food Chem., in press

Nakamura, K., Kanno, T., Ikai, H., Sato, E., Mokudai, T., Niwano, 
Y., Ozawa, T., and Kohno, M. (2010) Reevaluation of quantitative ESR spin trapping analysis of hydroxyl radical by applying sonolysis of water as a model system. Bull. Chem. Soc. Jpn., 83, 1037-1046.

Nakamura, K., Shirato, M., Ikai, H., Kanno, T., Sasaki, K., Kohno, M., and Niwano, Y. (2013) Photo-irradiation of proanthocyanidin as a new disinfection technique via reactive oxygen species formation. PLoS One, 8, e60053.

Nakamura, K., Yamada, Y., Ikai, H., Kanno, T., Sasaki, K., and Niwano, Y. (2012) Bactericidal action of photoirradiated gallic acid via reactive oxygen species formation. J. Agric. Food Chem., 60, 10048-10054.

Pryor, W. A. (1986) Oxy-radicals and related species: their formation, lifetimes, and reactions. Annu. Rev. Physio., 148, 657-667.

Roots, R., and Okada, S. (1975) Estimation of life times and diffusion distances of radicals involved in $\mathrm{x}$-ray-induced DNA strand breaks of killing of mammalian cells. Radiat. Res., 64, 306-320.

Sato, E., Mokudai, T., Niwano, Y., and Kohno, M. (2011) Kinetic analysis of reactive oxygen species generated by the in vitro reconstituted NADPH oxidase and xanthine oxidase systems. J. Biochem., 150, 173-181.

Schanderl, S. H. (1970) Tannins and related phenolics. In Methods in Food Analysis (Joslyn, M. A., ed.), pp.701-704, Academic Press, New York.

Vermeulen, N., Keeler, W. J., Nandakumar, K., and Leung, K. T. (2008) The bactericidal effect of ultraviolet and visible light on Escherichia coli. Biotechnol. Bioeng., 99, 550-556.

Yilmaz, Y., and Toledo, R. T. (2004) Major flavonoids in grape seeds and skins: antioxidant capacity of catechin, epicatechin, and gallic acid. J. Agric. Food Chem., 52, 255-260. 